\title{
Coloration of polyester fiber with natural dye henna (Lawsonia inermis L.) without using mordant: a new approach towards a cleaner production
}

\author{
M. A. Rahman Bhuiyan ${ }^{\text {* }}$, A. Ali' , A. Islam , M. A. Hannan' ${ }^{1}$ S. M. Fijul Kabir ${ }^{2}$ and M. N. Islam³
}

*Correspondence:

arahman@duet.ac.bd

${ }^{1}$ Department of Textile Engineering, Dhaka

University of Engineering and Technology, DUET,

Gazipur 1700, Bangladesh

Full list of author information

is available at the end of the

article

\begin{abstract}
The demand of natural colorants for the dyeing of textile fibers has been increasing gradually in recent years due to a growing global ecological awareness as well as a greater emphasis on a cleaner and greener production process. The eco-friendly dyeing of polyester fiber with natural dye henna is a novel approach that has extensively been studied in this article. To this end, the dyeing of polyester fiber with henna dye was conducted at different temperatures without using hazardous metallic mordants. Then the dyeing performance was investigated in terms of depth of shade measurement, analysis of colorimetric properties of color and assessment of color fastness properties of henna dyed polyester fabric samples. The amount of dye absorption by fiber and the resulting depth of shade were found to increase with increasing dyeing temperature. In case of colorfastness properties, all dyed substrates demonstrated excellent fastness ratings against washing, rubbing and perspiration with little to no deterioration of color. Moreover, the detailed morphological study revealed that surface structure of fiber remained unchanged after dyeing at an elevated temperature and pressure. So, the findings suggest that dyeing of polyester fiber with henna dye without any metallic mordants is a promising approach to get the desired dyeing performance alongside opening up an avenue for eco-friendly dyeing.
\end{abstract}

Keywords: Polyester fiber, Natural dye, Henna leaves, Eco-friendly dyeing, Cleaner production

\section{Introduction}

Polyester is a general name given to the fibers usually made from polyethylene terephthalate having ester functional group in their main chain and formed through the polycondensation reaction of a glycol (or diol) with a difunctional carboxylic acid (or diacid) (Edlund and Albertsson 2003). The presence of two functional groups of each reacting species results in the formation of a linear polyester molecule. Polyesters are of great importance as fiber materials in terms of volume and product value due to their versatility in various application sectors with relatively low raw material and production costs (Park and Kim 2014). Among all the classes of polyester fiber, the most commercially

(c) The Author(s) 2018. This article is distributed under the terms of the Creative Commons Attribution 4.0 International License (http://creativecommons.org/licenses/by/4.0/), which permits unrestricted use, distribution, and reproduction in any medium provided you give appropriate credit to the original author(s) and the source, provide a link to the Creative Commons license, and indicate if changes were made. 
important and long-established fiber material is polyethylene terephthalate (PET) which is an aliphatic-aromatic polymer being made up of terephthalic acid (TPA) and ethylene glycol (EG) (Deopura et al. 2008). The large molecules and inflexible structure of PET macromolecules lead to a compact and highly crystalline molecular arrangement of polyester fiber associated with a high melting point and glass transition temperature along with their insensitivity to moisture and various chemicals (Lewin 2007).

The highly crystalline structure and a lack of polarity make polyester fiber hydrophobic in nature (El-Nagar et al. 2006) that in turn resists any entry of water molecules into the polymer system and also imparts a limited swelling in water. Consequently, the hydrophobicity of polyester fiber restricts the diffusion of dye molecules into the fiber interior during dyeing (Peters and Ingamells 1973) that also makes the dyeing process exceedingly difficult at a low temperature. At a high temperature and pressure, the dyeing of polyester fiber is mainly carried out by synthetic colorants such as disperse dye (Aspland 1992; Fité 1995; Kim et al. 2005) owing to its very small particle size and non-ionic nature (Gohl and Vilensky 1983). However, in recent years there has been a renewed interest both in academia and textile industry due to mounting global awareness and environmental concerns that lead to several studies focusing on coloration of polyester fibers with natural dyes from various natural resources such as onion, madder, saffron, kola nut, dolu and curcumin (Ado et al. 2015; Shahin et al. 2014; El-Nagar et al. 2014). But still, any systematic investigation and application of henna dye on polyester fiber is rare despite its well-established use as a dye for textile fibers.

Henna commonly being known as lawsone or hennotannic acid, a red-orange pigment, is the chief constituent of henna leaves (Rehman et al. 2012). Based on the illustration of industrial classifications, lawsone is Natural Orange 6 and CI 75480 which is chemically known as 2-hydroxy-1,4-naphthoquinone (Scheme 1) and acts as a substantive dye for protein fiber as well as other textile fibers and imparts orange color on the substrate (Bhuiyan et al. 2017a). Again, like other natural dyes, it has several remarkable advantages, such as it does not pose any hazard to health, is easily harmonized with nature, with a little chemical reactivity and no adverse environmental problems. On the contrary, the application of metallic mordant which is a common practice in the dyeing process of natural colorants along with henna (Vankar 2000) hinders its environmental prospect as a potential substitute for synthetic dye.

Being primarily metallic salts, a mordant acts as a sort of glue that fixes fiber firmly with dye resulting in a durable color on the textile substrate. The process of mordanting

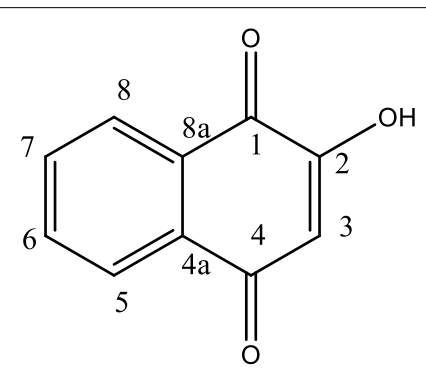

Scheme 1 Chemical structure of lawsone (2-hydroxy-1,4-naphthoquinone) 
usually enhanced the performance of dye besides achieving a wide spectrum of colors on both natural and synthetic textile fibers having extended shade ranges associated with colorfastness properties (Kadolph and Casselman 2004). Different types of metallic mordants (such as potash alum, iron, tin, copper and chrome) either individually or in combination are applied to the dyebath of natural colorants as well as henna in order to obtain the desired performance of dyed fibers (Kamel et al. 2011). However, to some extent, these metallic mordants are hazardous and normally generate wastewater that contains residual toxic metal ions from metal salts which may adversely impact the environment as well as public health (Shahid and Mohammad 2013; Lee et al. 2010). Hence, the main objectives of this study were to explore the scope of dyeing polyester fiber with henna dye at a high temperature and pressure without using any mordants followed by the analysis of color strength and colorfastness properties of the resulting dyed fabrics.

\section{Methods}

Materials

Pretreated 100\% polyester fabric (EPI 104; PPI 72 and GSM 69) was purchased from the local market of Bangladesh and used in all the experiments. For the dyeing of polyester fabric, natural dye henna (Lawsonia inermis L.) was brought from local market and used to obtain the dyestuff of lawsone, which is reddish brown in color. Ethanol $\left(\mathrm{C}_{2} \mathrm{H}_{5} \mathrm{OH}\right)$ for the extraction of dye from henna leaves was purchased from Merck, India.

\section{Extraction of henna dye}

Fresh leaves of henna were dried in the sunlight for 1 day and then dried at $80{ }^{\circ} \mathrm{C}$ for $1 \mathrm{~h}$ in an oven followed by washing and cleaning with distilled water (Bhuiyan et al. 2017b). Dried leaves were ground to powder form to ensure proper extraction results. The extracts were obtained by soaking the henna powder in water-ethanol mixture (90:10 $\mathrm{v} / \mathrm{v}$ ) at room temperature for $24 \mathrm{~h}$.

\section{Dyeing with henna dyes}

The dyeing of polyester fiber was carried out using the abovementioned extracts for $60 \mathrm{~min}$ at different temperatures $\left(90,100,110,120\right.$ and $\left.130{ }^{\circ} \mathrm{C}\right)$ with a material-to-liquor ratio of 1:40 for optimum dye exhaustion. The dyeing was performed by exhaust method for the shade of $20 \%$ on the weight of fabric (owf) in Sandolab infrared lab dyeing machine from Co-power Technology Ltd. Taiwan. After dyeing, the dyed fabric samples were washed in a bath with $1 \mathrm{~g} / \mathrm{L}$ of soaping agent at $60{ }^{\circ} \mathrm{C}$ temperature for $10 \mathrm{~min}$ as well as rinsed with cold water and then dried in a dryer. For the ease of identification, all the test fabric samples were coded as shown in Table 1.

Table 1 Test fabric sample coding

\begin{tabular}{ll}
\hline Test fabric type & Code \\
\hline Fabric sample dyed at $90{ }^{\circ} \mathrm{C}$ & $\mathrm{A}$ \\
Fabric sample dyed at $100^{\circ} \mathrm{C}$ & $\mathrm{B}$ \\
Fabric sample dyed at $110^{\circ} \mathrm{C}$ & $\mathrm{C}$ \\
Fabric sample dyed at $120^{\circ} \mathrm{C}$ & $\mathrm{D}$ \\
Fabric sample dyed at $130^{\circ} \mathrm{C}$ & $\mathrm{E}$ \\
\hline
\end{tabular}




\section{Measurement of color strength and related parameters}

The color yield value of henna dyed polyester fabric samples was analyzed by using color measurement spectrophotometer (Datacolor 650 from China). The depth of color of the dyed fabric was determined by analyzing the K/S value of a given dyed sample by Kubelka-Munk equation [Eq. (1) (Bhuiyan et al. 2013)].

$$
\frac{\mathrm{K}}{\mathrm{S}}=\frac{(1-\mathrm{R})^{2}}{2 \mathrm{R}}
$$

where R reflectance percentage; $\mathrm{K}$ absorption co-efficient; and S scattering co-efficient of dyes. This value was derived from the attenuation ratio of light due to absorption and scattering, which was found based on reflectance.

Colorimetric properties of the dyed fabrics such as Lightness $\left(L^{*}\right)$, redness-greenness $\left(a^{*}\right)$, yellowness-blueness $\left(b^{*}\right)$, chroma $\left(c^{*}\right)$ and hue $\left(h^{\circ}\right)$ were evaluated according to AATCC test method 173-2006 in illuminant D65, large area view and CIE $10^{\circ}$ standard observer (Bhuiyan et al. 2016a). Each sample was folded twice to give an opaque view and color reflectance was measured four times at different parts of the fabric surface.

\section{Determination of colorfastness properties}

The colorfastness property of dyed fabric samples against washing was conducted according to ISO 105-C03: 1989 by wash fastness tester (Gyrowash 415/8 from James H. Heal and Co., UK). Colorfastness to perspiration was assessed according to ISO 105E04:2013 by perspiration fastness tester (Perspirometer HX-30 from James H. Heal and Co., UK). The change and staining (with multifiber fabric SDC DW) of color due to washing and perspiration were assessed by comparing the untreated fabric with the treated fabric samples with respect to the ratings of color change and color staining gray scales. The color fastness to rubbing was performed according to ISO 105-X12:2016 by rubbing fastness tester (Crockmeter 670 from James H. Heal and Co., UK). The assessment was performed by staining of color on white crocking cloth (bleached white cotton fabric) in both dry and wet condition. All the analyses of test fabric samples were conducted after conditioning the dyed fabrics under the testing atmosphere (temperature $27 \pm 2{ }^{\circ} \mathrm{C}$ and relative humidity $65 \pm 2 \%$ ) for $24 \mathrm{~h}$ (Saville 1999).

\section{Characterization}

The determination of specific functional groups or chemical bonds that may form between polyester fiber and henna dye after dyeing was done by Fourier Transform Infrared (FTIR) spectrophotometer (Cary 630) from Agilent Technologies, USA. FTIR spectra were taken by absorption mode and measured by using potassium bromide $(\mathrm{KBr})$ pellets made of finely cut and ground undyed and dyed polyester fibers and henna powder. The surface morphology of undyed and dyed polyester fabric samples was observed by using the Phenom Pro scanning electron microscope (SEM) from PhenomWorld BV, Netherlands. The acceleration voltage of work was $5 \mathrm{kV}$ with magnification up to $1050 \times$. 


\section{Results and discussion}

\section{Analysis of color strength}

The color strength or depth of shade of henna dyed fabric samples was investigated by $\mathrm{K} / \mathrm{S}$ value which numerically represents the nature of the coloring material layer and an easy way to determine a color as a concentration due to the light absorbing and scattering (Bhuiyan et al. 2016b). The function $\mathrm{K} / \mathrm{S}$ is directly proportional to the concentration of colorant in the substrate and the values found for all the experimental fabric samples are shown in Fig. 1.

The change of color strength i.e. K/S values of polyester fabrics dyed with henna at different temperatures are shown in Fig. 1. A higher K/S value indicates a greater amount of dyestuff in the fabric resulting in the deeper shade. The shortest bar diagram because of lower K/S value exhibited by the fabric samples dyed at $90{ }^{\circ} \mathrm{C}$ specifies lower absorption of dye while fiber dyed at $130{ }^{\circ} \mathrm{C}$ showed a longer bar due to a higher $\mathrm{K} / \mathrm{S}$ value leads to a better absorption of dye (Fig. 2).

The reason for more absorption of henna dye by polyester fiber due to high temperature is not thoroughly investigated as yet so far. But it may be suggested that an elevated temperature and pressure employed in dyeing may open up the pores of the polyester macromolecular arrangement. As discussed earlier, polyester fiber is a very compact and highly crystalline in nature as well as it is insensitive to moisture and various chemicals. Dyeing of polyester fiber at a high temperature most likely allows the minute dye particles to penetrate deep into the fiber interior resulting in a greater absorption of dye by fiber (Broadbent 2001).

\section{Color specification and relative color strength}

The colorimetric properties of the experimental fabric samples were performed using spectrophotometer through CIELab system. The lightness value of color (from $100=$ white to $0=$ black) represents by $L^{*}$, the higher the lightness value indicates the lower the color yield by dyed fabric. Again $a^{*}$ and $b^{*}$ value characterize the tone of the

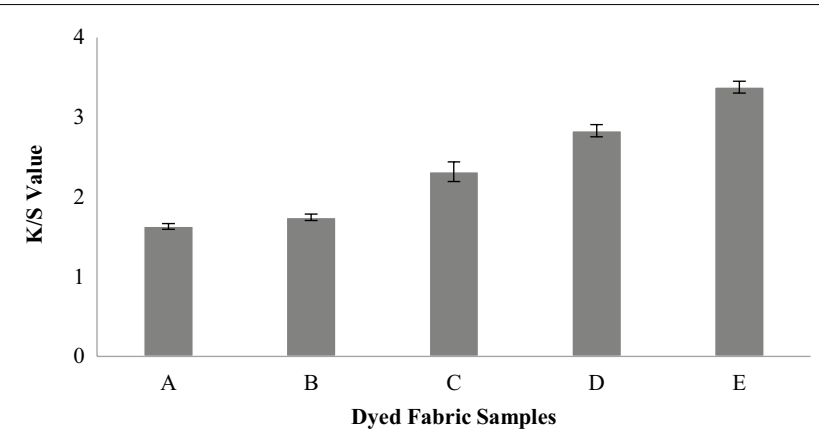

Fig. 1 The gradual increment of color strength (K/S value at $\lambda_{\max }=420 \mathrm{~nm}$ ) of henna dyed polyester fiber with the increase of temperature
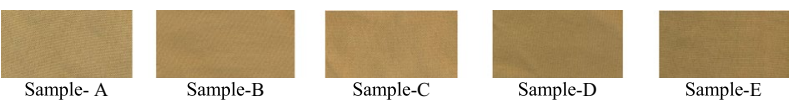

Fig. 2 Shade card of henna dyed polyester fabric samples at different temperatures 
color, positive values of $\mathrm{a}^{*}$ and $\mathrm{b}^{*}$ stand for redder and yellower tones while negative shows greener and bluer tones respectively (Ali et al. 2009). Moreover, c* values represent the chroma or intensity of color and $\mathrm{h}^{\circ}$ corresponds to hue angle.

Table 2 represents the colorimetric characteristics of polyester fabrics after coloration with henna dye. The lower $L *$ values of dyed samples indicate a more intensity of color with the increase in dyeing temperature causing a greater absorption of the dye. Accordingly, the increase in $c^{*}$ value of dyed fabric with the increase in dyeing temperature signifies a higher depth of shade of the dyed fabric. Furthermore, the positive $a^{*}$ and $b^{*}$ values suggest that the combination of red and yellow tones leads to in the orange color of the dyed fabric sample which is the characteristic of the natural color of lawson pigment of henna dye (Bhuiyan et al. 2017b).

\section{Colorfastness properties of dyed fabric}

Colorfastness is the property of a dye to retain its color when the dyed or printed textile material is exposed to various environmental conditions. The assessment of colorfastness against washing and perspiration was carried out in the usual way in terms of the gray scale values for staining of adjacent multifiber fabric and alteration in shade. However, rubbing fastness was evaluated only color staining option in both dry and wet condition. The colorfastness ratings of all experimental samples are tabularized in the Tables 3,4 and 5 respectively.

The colorfastness ratings against washing and perspiration in Tables 3 and 4 show that polyester fabrics dyed with henna dye have an almost identical fastness ratings of 'very good' to 'excellent' (within numerical grade 4-5 and 5) with a very little variation in the depth of shades. Again, no or a little staining of color onto adjacent multifiber fabric

Table 2 Spectrophotometer characterization of henna dyed polyester fabric samples at different temperatures

\begin{tabular}{llllll}
\hline Test fabric samples & $\boldsymbol{L}^{*}$ & $\boldsymbol{A}^{*}$ & $\boldsymbol{B}^{*}$ & $\boldsymbol{C}^{*}$ & $\boldsymbol{H}^{\mathbf{*}}$ \\
\hline A & 63.87 & 6.80 & 16.15 & 18.03 & 67.43 \\
B & 62.95 & 7.77 & 18.14 & 19.79 & 67.17 \\
C & 61.43 & 8.60 & 19.56 & 20.72 & 66.90 \\
D & 58.26 & 8.83 & 20.81 & 22.14 & 66.34 \\
E & 57.03 & 9.58 & 21.86 & 23.87 & 65.01 \\
\hline
\end{tabular}

Table 3 Colorfastness to washing (color change and color staining) of henna dyed polyester fabric samples

\begin{tabular}{llllllll}
\hline Test fabric samples & \multicolumn{6}{l}{ Washing fastness ratings } \\
\cline { 2 - 7 } & \multicolumn{2}{l}{ Color change change } & \multicolumn{6}{l}{ Color staining } & & & \\
\cline { 3 - 7 } & & Acetate & Cotton & Nylon & Polyester & Acrylic & Wool \\
\hline A & 5 & 5 & 5 & 5 & 5 & 5 & 5 \\
B & 5 & 5 & 5 & 5 & 4 & 5 & 5 \\
C & 5 & 5 & 5 & 5 & 4 & 5 & 5 \\
D & $4-5$ & 5 & 5 & $4-5$ & 4 & 5 & $4-5$ \\
E & $4-5$ & 5 & $4-5$ & $4-5$ & $4-5$ & 5 & $4-5$ \\
\hline
\end{tabular}


Table 4 Colorfastness to perspiration (color change and color staining) of henna dyed polyester fabric samples

\begin{tabular}{llllllll}
\hline Test fabric samples & \multicolumn{6}{l}{ Washing fastness ratings } \\
\cline { 2 - 7 } & \multicolumn{2}{l}{ Color change change } & \multicolumn{2}{l}{ Color staining } \\
\cline { 3 - 8 } & & Acetate & Cotton & Nylon & Polyester & Acrylic & Wool \\
\hline A & 5 & 5 & 5 & 5 & 5 & 5 & 5 \\
B & 5 & 5 & 5 & 5 & 4 & 5 & 5 \\
C & 5 & 5 & 5 & 5 & 4 & 5 & 5 \\
D & $4-5$ & 5 & $4-5$ & $4-5$ & $4-5$ & 5 & $4-5$ \\
E & $4-5$ & $4-5$ & $4-5$ & $4-5$ & $4-5$ & $4-5$ & $4-5$ \\
\hline
\end{tabular}

Table 5 Colorfastness to rubbing (dry and wet) of henna dyed polyester fabric samples

\begin{tabular}{llllll}
\hline $\begin{array}{l}\text { Test fabric } \\
\text { Samples }\end{array}$ & $\begin{array}{l}\text { Rubbing fastness } \\
\text { (Warp direction) }\end{array}$ & & & \multicolumn{2}{l}{$\begin{array}{l}\text { Rubbing fastness } \\
\text { (Weft direction) }\end{array}$} \\
\cline { 2 - 3 } & Dry & Wet & & Dry & Wet \\
\hline A & 5 & 5 & 5 & 5 \\
B & 5 & 5 & 5 & 5 \\
C & 5 & 5 & 5 & 5 \\
D & 5 & $4-5$ & 5 & $4-5$ \\
E & 5 & $4-5$ & 5 & \\
\hline
\end{tabular}

due to washing or perspiration signifies remarkable colorfastness properties of polyester fiber dyed with henna. Moreover, no significant change in color was observed in case of dry and wet rubbing of dyed fabric (Table 5). The excellent colorfastness properties against washing, perspiration and rubbing demonstrated by polyester fiber dyed with henna may be attributed to its highly crystalline structure and hydrophobic nature (Bhuiyan et al. 2017a). High crystallinity can trap the dye molecules inside the fiber strongly while hydrophobicity restricts any entry of water molecules into the polymer system combined with a limited swelling during washing for the removal of excess dye molecules from fiber interior.

\section{Characterization of dyed fabric samples}

\section{FTIR spectroscopic analysis}

The chemical characteristics of henna dye along with undyed and dyed polyester fiber samples were studied by FTIR spectroscopy. The possible change in molecular structure of polyester fiber due to its interaction with henna dye after dyeing was thoroughly examined by scanning the test samples in the infrared light source.

The FTIR spectra of henna dye and its chemical interaction with polyester fiber after dyeing are shown in Fig. 3. The detailed infrared (IR) spectrum of lawsone indicates the presence of $\mathrm{C}=\mathrm{C}$ vibrational bands of the aromatic ring at 1513 and $1522 \mathrm{~cm}^{-1}$ and the carbonyl-stretching region is observed at 1615 and $1692 \mathrm{~cm}^{-1}$ (Musa and Gasmelseed 2012). The bond at $3214 \mathrm{~cm}^{-1}$ indicates the stretching $\mathrm{O}-\mathrm{H}$ which overlays the $\mathrm{C}-\mathrm{H}$ vibrations (Mahkam et al. 2014). In addition, the typical band of $\mathrm{O}-\mathrm{H}$ stretching 

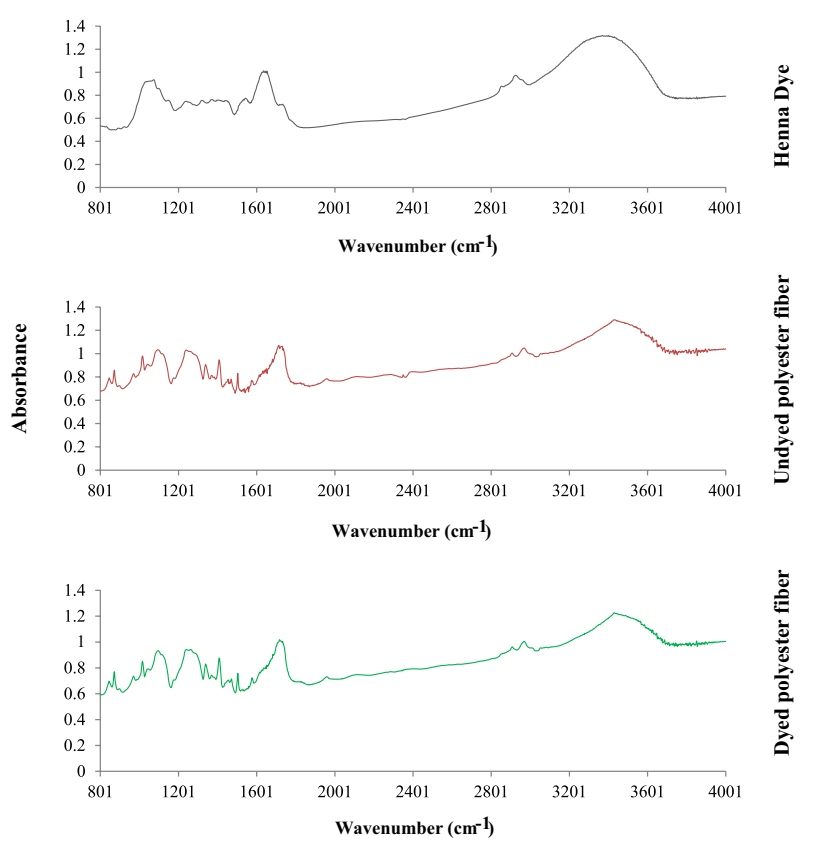

Fig. 3 FTIR absorption spectra of henna dye and polyester fiber samples at dyed and undyed condition

for 2-naphthol lies at $3610 \mathrm{~cm}^{-1}$ whereas that for lawsone is placed much lower at $3401 \mathrm{~cm}^{-1}$ that may be due to keto-enol tautomerism (Amro et al. 1993).

Again, in case of undyed polyester fiber the weak $\mathrm{C}-\mathrm{H}$ stretching, $\mathrm{C}-\mathrm{H}$ bending and moderately intense $\mathrm{C}-\mathrm{C}$ out of plane bending vibrations of the benzene rings are observed at 2957, 845 and $871 \mathrm{~cm}^{-1}$ respectively (Parvinzadeh and Ebrahimi 2011). The intramolecularly $\mathrm{O}-\mathrm{H}$ bonded to $>\mathrm{C}=\mathrm{O}$ groups and $\mathrm{O}-\mathrm{H}$ out-of-plane bending in terminal carboxylic groups in PET macromolecular chain bands appear at 3421 and $1090 \mathrm{~cm}^{-1}$ (Parvinzadeh et al. 2010). In addition, the strong $\mathrm{C}=\mathrm{O}$ symmetric stretching of carbonyl groups at $1714 \mathrm{~cm}^{-1}$ corresponds to the esteric bonds of polyethylene terephthalate molecule along with an asymmetric stretching small band at $1572 \mathrm{~cm}^{-1}$. However, no significant changes were observed in bands or their intensities in case of dyed polyester fiber samples. This trivial change indicates that no chemical bond between polyester fiber and henna dye due to dyeing was formed and it may be assumed that the interaction between the materials is only of physical nature or van der Waals forces might be at play.

\section{Morphological study}

The study on surface morphology of undyed and dyed polyester fabric samples was conducted by the scanning electron microscope (SEM). The possible change in the morphological structure of polyester fiber due to dyeing at a high temperature was investigated by comparing with that of undyed fiber after creating images at different magnifications.

The scanning electron microscopic images of undyed and dyed polyester fibers are shown in Fig. 4. It has been observed that the surface structure of polyester fiber remains unchanged without any apparent rupture because of its processing at a high temperature $\left(130{ }^{\circ} \mathrm{C}\right)$. The unaffected morphological structure indicates an intact physical property of 


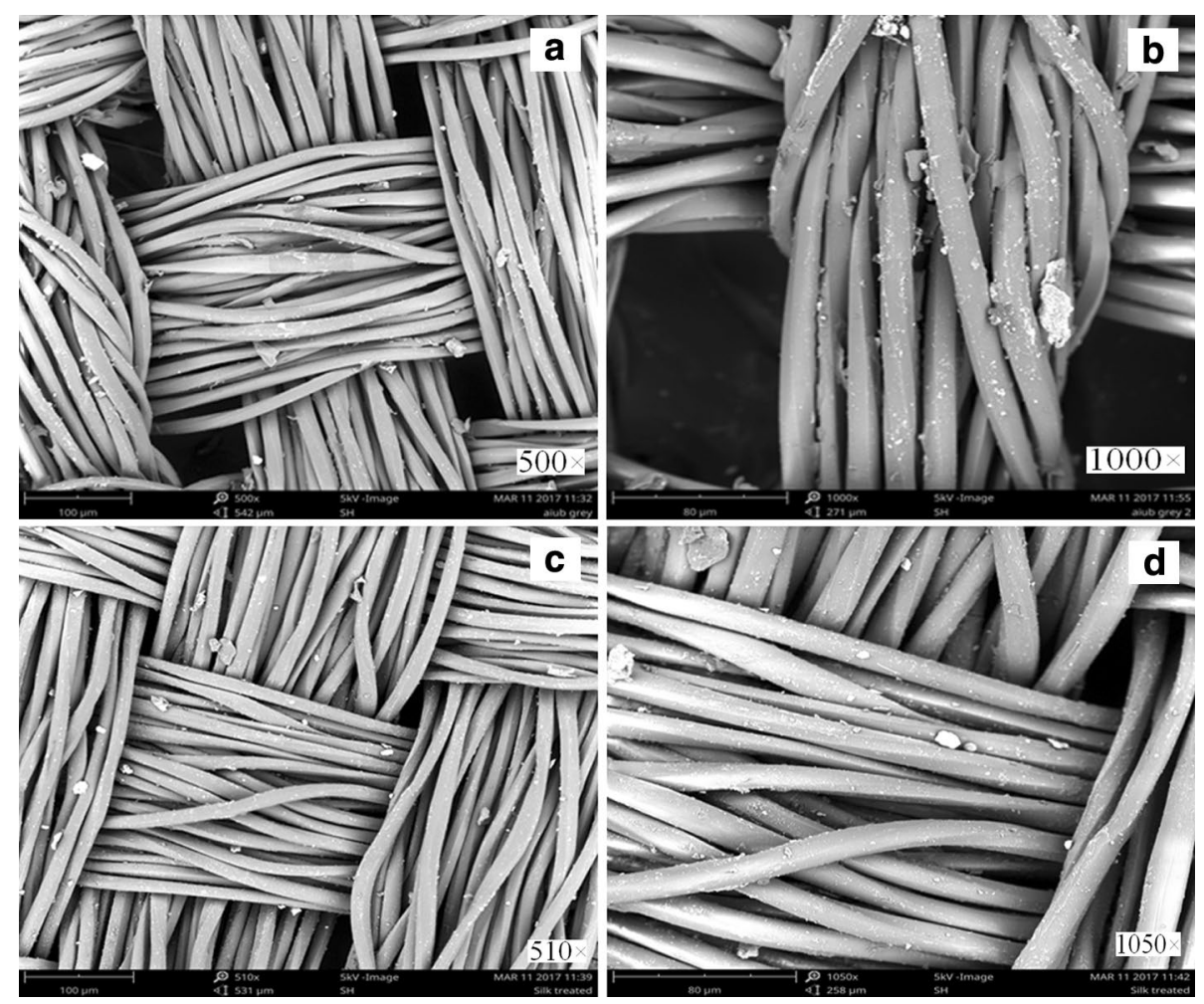

Fig. 4 SEM images of undyed $(\mathbf{a}, \mathbf{b})$ and dyed $(\mathbf{c}, \mathbf{d})$ polyester fiber samples at different magnifications

fiber and hence, it can be predicted that physical or mechanical properties of polyester fiber will remain unaffected due to dyeing with henna at an elevated temperature and pressure.

\section{Conclusions}

The coloration of polyester fiber with natural dye henna at a high temperature and pressure with the prospects of a mordant-free dyeing has been extensively investigated. The detailed experimental results have revealed that dyeing of polyester fiber with henna dye at an elevated temperature can appreciably enhance the uptake of dye by fiber leading to an increased depth of shade. Besides, due to an intense trapping of dye in the fiber interior, the dyed fabric samples also exhibited an excellent colorfastness property against washing, perspiration and rubbing. In addition, the unchanged morphological structure of fiber predicts that the mechanical properties of fiber which will remain unaffected after dyeing. Therefore, the findings of the research suggest a potential application of henna dye on polyester fiber at a high temperature without using mordants. As a result, any deleterious environmental effects can be reduced significantly by avoiding harmful metals in the wastewater and this could usher in a new way to a cleaner and greener textile dyeing process.

\section{Authors' contributions}

MAR and MAH contributed to the conception of the study, designed the experiment and drafted the manuscript. AA and Al coordinated the experimental analysis and characterization. MFK and MNI interpreted data and submission of the manuscript. All authors read and approved the final manuscript. 


\begin{abstract}
Author details
${ }^{1}$ Department of Textile Engineering, Dhaka University of Engineering and Technology, DUET, Gazipur 1700, Bangladesh.

${ }^{2}$ Department of Textile, Apparel Design \& Merchandising, Louisiana State University, Baton Rouge, LA 70803, USA.

${ }^{3}$ Department of Chemistry, Dhaka University of Engineering and Technology, DUET, Gazipur 1700, Bangladesh.
\end{abstract}

\title{
Competing interests
}

The authors declare that they have no competing interests.

\section{Ethics approval and consent to participate}

Not applicable.

\section{Publisher's Note}

Springer Nature remains neutral with regard to jurisdictional claims in published maps and institutional affiliations.

Received: 4 June 2017 Accepted: 24 September 2017

Published online: 28 January 2018

\section{References}

Ado, A., Musa, H., Gumel, S., \& Yahaya, H. (2015). Eco-friendly dyeing of cotton and polyester fabrics with natural dyes extracted from different varieties of Kola nuts. International Journal of Chemical Sciences, 1(1), 6-11.

Ali, S., Hussain, T., \& Nawaz, R. (2009). Optimization of alkaline extraction of natural dye from Henna leaves and its dyeing on cotton by exhaust method. Journal of cleaner production, 17(1), 61-66.

Amro, B., James, K., \& Turner, T. (1993). A quantitative study of dyeing with lawsone. Journal of the Society of Cosmetic Chemists, 45, 159-165

Aspland, J. R. (1992). Disperse dyes and their application to polyester. Textile Chemist and Colorist, $24,18$.

Bhuiyan, M. R., Islam, A., Ali, A., \& Islam, N. (2017a). Color and chemical constitution of natural dye Henna (Lawsonia inermis L.) and its application in the coloration of textiles. Journal of Cleaner Production, 167, 14-22.

Bhuiyan, M. A. R., Islam, A., Islam, S., Hossain, A., \& Nahar, K. (2017b). Improving dyeability and antibacterial activity of Lawsonia inermis L. on jute fabrics by chitosan pretreatment. Textiles and Clothing Sustainability, 3(1), 1-10.

Bhuiyan, M. R., Rahman, M. M., Shaid, A., Bashar, M. M., \& Khan, M. A. (2016a). Scope of reusing and recycling the textile wastewater after treatment with gamma radiation. Journal of Cleaner Production, 112, 3063-3071.

Bhuiyan, M. R., Shaid, A., Bashar, M. M., Haque, P., \& Hannan, M. A. (2013). A novel approach of dyeing jute fiber with reactive dye after treating with chitosan. Open Journal of Organic Polymer Materials, 3(4), 87-91.

Bhuiyan, M. R., Shaid, A., Bashar, M. M., \& Sarkar, P. (2016b). Investigation on dyeing performance of basic and reactive dyes concerning jute fiber dyeing. Journal of Natural Fibers, 13(4), 492-501.

Broadbent, A. D. (2001) Basic principles of textile coloration society of dyers and colorists. West Yorkshire: Society of Dyers and Colorists.

Deopura, B., Alagirusamy, R., Joshi, M., \& Gupta, B. (2008). Polyesters and polyamides. Amsterdam: Elsevier.

Edlund, U., \& Albertsson, A.-C. (2003). Polyesters based on diacid monomers. Advanced Drug Delivery Reviews, 55(4), 585-609.

El-Nagar, K., Abou Elmaaty, T., \& Raouf, S. (2014). Dyeing of polyester and polyamide synthetic fabrics with natural dyes using eco-friendly technique. Journal of Textiles. http://dx.doi.org/10.1155/2014/363079.

El-Nagar, K., Saudy, M., Eatah, A., \& Masoud, M. (2006). DC pseudo plasma discharge treatment of polyester textile surface for disperse dyeing. Journal of the Textile Institute, 97(2), 111-117.

Fité, F. C. (1995). Dyeing polyester at low temperatures: kinetics of dyeing with disperse dyes. Textile Research Journal, 65(6), 362-368.

Gohl, E., \& Vilensky, L. (1983). Textile Science. An Explanation of Fiber Properties (p. 48). Melbourne: Longman Chesire.

Kadolph, S. J., \& Casselman, K. D. (2004). In the bag: contact natural dyes. Clothing and Textiles Research Journal, 22(1-2), $15-21$.

Kamel, M. M., Abdelghaffar, F., \& El-Zawahry, M. M. (2011). Eco-friendly dyeing of wool with a mixture of natural dyes. Journal of Natural Fibers, 8(4), 289-307.

Kim, T. K., Son, Y. A., \& Lim, Y. J. (2005). Thermodynamic parameters of disperse dyeing on several polyester fibers having different molecular structures. Dyes and Pigments, 67(3), 229-234.

Lee, Y. H., Hwang, E. K., Jung, Y. J., Do, S. K., \& Kim, H. D. (2010). Dyeing and deodorizing properties of cotton, silk, wool fabrics dyed with Amur Corktree, Dryopteris crassirhizoma, Chrysanthemum boreale, Artemisia extracts. Journal of Applied Polymer Science, 115(4), 2246-2253.

Lewin, M. (2007). Handbook of fiber chemistry. Boca Raton: CRC Press LLC.

Mahkam, M., Nabati, M., \& Rahbar Kafshboran, H. (2014). Isolation, identification and characterization of lawsone from henna leaves powder with soxhlet technique. Iranian Chemical Communication, 2, 34-38.

Musa, A. E., \& Gasmelseed, G. A. (2012). Characterization of Lawsonia inermis (Henna) as vegetable tanning material. Journal of forest products \& industries, 1(2), 35-40.

Park, S. H., \& Kim, S. H. (2014). Poly (ethylene terephthalate) recycling for high value added textiles. Fashion and Textiles, $1(1), 1-17$.

Parvinzadeh, M., \& Ebrahimi, I. (2011). Atmospheric air-plasma treatment of polyester fiber to improve the performance of nanoemulsion silicone. Applied Surface Science, 257(9), 4062-4068. 
Parvinzadeh, M., Moradian, S., Rashidi, A., \& Yazdanshenas, M. E. (2010). Effect of the addition of modified nanoclays on the surface properties of the resultant polyethylene terephthalate/clay nanocomposites. Polymer-plastics technology and engineering, 49(9), 874-884.

Peters, R. H., \& Ingamells, W. (1973). Theoretical aspects of the role of fibre structure in dyeing. Coloration Technology, 89(11), 397-405

Rehman, F.-U., Adeel, S., Qaiser, S., Bhatti, I. A., Shahid, M., \& Zuber, M. (2012). Dyeing behaviour of gamma irradiated cotton fabric using Lawson dye extracted from henna leaves (Lawsonia inermis). Radiation Physics and Chemistry, 81(11), 1752-1756.

Saville, B. P. (1999). Physical testing of textiles. Amsterdam: Elsevier.

Shahid, M., \& Mohammad, F. (2013). Recent advancements in natural dye applications: a review. Journal of Cleaner Production, 53, 310-331.

Shahin, M., Ahmed, R., \& Marie, M. (2014). Optimizing the dyeing process of alkali-treated polyester fabric with dolu natural dye. International Journal of Engineering Research and Applications, 4, 35-40.

Vankar, P. S. (2000). Chemistry of natural dyes. Resonance, 5(10), 73-80.

Submit your manuscript to a SpringerOpen ${ }^{\circ}$ journal and benefit from:

Convenient online submission

- Rigorous peer review

Open access: articles freely available online

- High visibility within the field

Retaining the copyright to your article

Submit your next manuscript at $\gg$ springeropen.com 